\title{
UNSUR KARAKTER CERITA RAKYAT SI MARDAN
}

\author{
Rosmawati Harahap ${ }^{1}$, Alkausar Saragih ${ }^{2}$ \\ ${ }^{1}$ Dosen Program Studi Magister Pendidikan Bahasa Indonesia Pascasarjana \\ ${ }^{2}$ Dosen Fakultas Keguruan dan Ilmu Pendidikan \\ UMN Al Washliyah \\ dahlanrahmawati59@gmail.com \\ saragih_al78@umnaw.ac.id
}

\begin{abstract}
Abstrak
Tujuan penelitian ini ingin mendeskripsikan unsur karakter yang unggul pada tokoh cerita Si Mardan dan unsur karakter yang gagal pada tokoh cerita Si Mardan. Metode penelitiannya adalah deskriptif kualitatif dengan teknik pengumpulan datanya sesuai teknik studi dokumen dan wawancara. Objek penelitiannya adalah cerita rakyat Si Mardan yang terdapat dalam teks karangan Sahril. Hasil penelitian ini terdapat sembilan unsur karakter cerita rakyat Si Mardan yang berfungsi sebagai prasarana didaktis dalam cerita rakyat Melayu. Unsur karakter bangsa yang terdapat dalam cerita rakyat Si Mardan secara umum yakni (1) nilai kejujuran, (2) nilai toleransi (3) nilai disiplin (d) nilai kerja keras, (5) mandiri, (6) nilai rasa ingin tahu, (7) nilai cinta tanah air (8) nilai bersahabat, dan (9) romantis; dan sebagai unsur karakter yang unggul pada tokoh cerita Si Mardan adalah karakter kejujuran dan disiplin sebagai pilar pembangunan karakter dan pendidikan bangsa. Cerita rakyat Si Mardan sebagai anak durhaka adalah kisah palsu yang disengaja dikisahkan anak yan tidak berketaatan. Unsur karakter unggul yang dimiliki Si Mardan adalah unsur karakter bangsa yang bersifat jujur dan disiplin.
\end{abstract}

Kata kunci: cerita rakyat, pembangunan karakter bangsa, pilar pendidikan.

\begin{abstract}
The purpose of this study would like to describe the elements of a superior character on the character of the folklore of Si Mardan and elements of characters that failed on the character of the folklore of Si Mardan. The research method is descriptive qualitative with data collection technique according to document study, interview. The object of his research is the folklore of Si Mardan contained in the text. The results of this research are nine elements of folklore Si Mardan character that serves as didactic infrastructure in Malay folklore. The elements of the nation's character in the folklore Si Mardan are (1) the value of honesty, (2) the value of tolerance (3) the value of discipline (d) the value of hard work, (5) independent, (6) the value of curiosity, (7) the value of love homeland (8) friendly values, and (9) romantic; so superior character is honesty and discipline as nation character building and education pillar. The folklore of Si Mardan as a son of lawlessness is a deliberate false story narrated a child who is not powerful. Elements of superior character owned by Si Mardan is an element of an honest and disciplined nation character.
\end{abstract}

Keywords: si mardan folklore, nation character building, education pillar.

\section{PENDAHULUAN}

Harahap (2015) menghimbau agar pegiat keliterasian karya sastra pengarang Sumatera Utara dipublikasikan. Banyak penulis dan sastrawan yang berasal dari Sumatera Utara tidak seterkenal dari Jawa seperti
Agus Sarjono, Massardi (2016), dan lain-lain. Padahal pegiat sastra nusantara dan budaya Melayu banyak pengarangnya yang berdomisili di Medan. OK Sahril (2012), Shafwan Hadi Umry dalam Sinaga (2017). Tiflatul Husna, Chairani adalah penulis cerita rakyat Sumatera Utara. 
OKSahril telah menjadi orang yang dirujuk untuk menceritakan $\mathrm{Si}$ Mardan. Menurutnya cerita rakyat $\mathrm{Si}$ Mardan adalah legenda tentang terjadinya pulau Si Mardan di kawasan pantai Tanjungbalai. Isi ceritanya berkaitan dengan watak tokoh cerita yang mencerminkan nilai karakter bangsa yang harus ditiru generasi penerus. Namun masih ada nilai karakter tokoh cerita Si Mardan yang tidak perlu ditiru siswa Indonesia karena menyimpang dari sebagian karakter bangsa yang diimplementasikan oleh tokoh cerita $\mathrm{Si}$ Mardan. Kebijakan Nasional Pembangunan Karakter Bangsa 20102025. Satuan pendidikan berwahana pembinaan dan pengembangan karakter siswa yang dilakukan secara formal di lingkungan sekolah. Pemberdayaannya dapat dilakukan melalui: (a) regulasi tentang pengintegrasian pembelajaran karakter dalam semua mata pelajaran, (b) meningkatkan kapasitas sekolah sebagai wahana pendidikan karakter melalui pelatihan para guru, (c) penyediaan sumber- sumber belajar yang terkait dengan upaya pengembangan karakter siswa dan (d) pemberian penghargaan kepada satuan pendidikan yang telah berhasil mengembangkan budaya karakter.

Karakteristik pembelajaran merupakan usaha sadar, perencanaan, etika yang terintegrasi dalam KI-1, KI2, KI-3, dan KI dalam Kurikulum 2013. Pembelajaran etika moral berorang tua dan bermertua terimplisit dalam teks cerita itu. Karakter bangsa Indonesia dicantumkan dalam Perda tahun

2012. Perda ini sudah mencakup unsur karakter individu secara universal. (1) kedamaian, (2) menghargai, (3) kerja sama, (4) kebebasan, (5) kebahagiaan, (6) kejujuran, (7) kerendah-hatian, (8) kasih sayang, (9) tanggung jawab, (10) kesederhanaan,
(11) menghargai, dan (12) persatuan. Sedangkan delapan belas karakter bangsa Indonsesia masih uji coba supaya menjadi ciri khas karakter bangsa berdasarkan filosofis Pancasila. Karakter yang sudah umum diketahui guru atau pendidik di Indonesia. Karakter religius, bangsa Indonesia sesuai Kurikulum 2013.

"Jujur, toleransi, disiplin, kerja keras, kreatif, mandiri, demokratis, rasa ingin tahu, semangat kebangsaan, cinta tanah air, menghargai prestasi, cinta damai, bersahabat/komunikatif, gemar membaca, peduli lingkungan, peduli sosial, tanggung jawab."

Delapan belas karakter bangsa Indonesia didokumentasi dan telah disosialisasikan secara implisit maupun eksplisit. Keintegrasiannya dalam silabus Kurikulum Pendidikan Bangsa Indonesia. Kedelapan belas karakter bangsa Indonesia tersebut secara hakikatnya berdimensi spiritual, moral, dan nilai. Dengan demikian performasi perilaku seseorang dinilai menurut hakikat nilai religi, moral (akhlak), dan nilai yang sesuai dengan filsafat Pancasila. Oleh karena itu, peneliti mengukur nilai moral tokoh cerita Si Mardan adalah didasarkan atas nilai yang berdasarkan filsafat Pancasila. Etika yang terkandung dalam praktik hidup berkehidupan di Indonesia disesuaikan dengan sila kedua yaitu Kemanusiaan yang adil dan beradab. Dengan demikian seseorang berhak menilai perbuatan seseorang di Indonesia atas dasar nilai filsafat Pancasila. Rumusan masalah penelitian ini yaitu unsur karakter apakah yang Unggul pada tokoh cerita Si Mardan; (2) unsur karakter apakah yang gagal pada tokoh cerita Si Mardan? 


\section{METODE}

\subsection{Metode dan Pendekatan Penelitian}

Penggunaan metode dalam penelitian ini adalah metode deskriptif analitik. Aminuddin. (1990) beracuan beberapa prinsip dan metode untuk mendeskripsikan teks dalam mengkaji sastra. Rujukan lain adalah buku Metodologi Penelitian Sastra, (Jabrohim, 2005). Kajian yang menyajikan data sesuai sumber lisan dan tertulis (Ratna, 2010) yang dihasilkan secara empiris. Sinar, dan Takari (2015) menjelaskan cara menganalisis teks tradisi lisan.

Hasil penelitian dideskripsikan lalu dianalisis dan ditafsirkan sesuai dengan teori pengembangan materi cerita rakyat.

Langkah ini dilakukan untuk dapat memahami jalan cerita berbentuk folklor secara utuh dan untuk memahami sekilas unsur intrinsik yang terdapat di dalamnya. Pendekatan untuk memahaminya maka peneliti menggunakan teknik analisis dengan pendekatan strukturalisme dan semantik.

Pendekatan Strukturalisme disamakan dengan pendekatan objektif dalam mengkaji sastra, pendekatan (penelitian) kesusasteraan yang menekankan pada kajian hubungan antarunsur (intrinsik). Bagian ekstrinsiklah yang dianalisis dalam cerita Si Mardan. Buku acuan yang digunakan untuk megidentifikasi teks cerita Si Mardan yang berciri anak durhaka dari segi teks tertulis tentang sikap Si Mardan sewaktu bertemu dengan Ibu Inang Tagor; buku metode penelitian Panuti Sudjiman (1988) berjudul Memahami Cerita Rekaan, dan karangan Jabrohim (2005) yang berjudul Metodologi Penelitian Sastra. Harahap (2012) peneliti yang menggunakan teknik analisis data secara deskriptf kualitatif dan tesis rujukannya menggunakan studi dokumentasi dan observasi lokasi folklor Si Mardan di Sumatera Utara. Lokasi ceritanya di daerah Toba, Sungai Asahan, dan daerah pesisir dekat Kota Tanjungbalai Provinsi Sumatera Utara.

\subsection{Instumen Penelitian}

Intrumen penelitian adalah peneliti sendiri yang berkompetensi pengumpulan data dengan studi observasi dan dokumentasi serta wawancara

\subsection{Observasi Lokasi Cerita}

Dengan melakukan untuk mendahului pengumpulan data dengan tujuan untuk mendapatkan gambaran yang tepat mengenai obyek penelitian yaitu lokasi terjadinya terjadinya cerita yaitu daerah Toba, Pantai dekat Kota Tanjungbalai di Kabupaten Asahan.

\subsection{Studi dokumentasi}

Sahril (2012) membukukan dari cerita

Si Mardan yang diserap dari beberapa pelisan ceritanya. Adakalanya peneliti berdiskusi kepada penulis buku yang menjadi sumber data utama. Sahril adalah penulis buku tentang cerita rakyat Sumatera Utara yang berisi cerita Si Mardan. Hal ini dimaksudkan untuk mengetahui lebih jelas data yang telah ada yang nantinya sebagai bahan perbandingan dalam penelitian ini. Buku rujukan cerita rakyat ini adalah buku karangan Sahril dan Shafwan Hadi Umry serta film youtube Si Mardan.

\section{Wawancara}


Dalam hal ini akan digabungkan dengan tiga model wawancara yang meliputi: Wawancaraa terstruktur yang sesuai disain model pengembangan pembelajaran.

\section{HASIL DAN PEMBAHASAN}

\section{Deskripsi Nilai Pendidikan Unsur Karakter}

Cerita rakyat Si Mardan berpenjelasan yakni unsur nilai pendidikan karakter yang tersemat dalam teks cerita Si Mardan terlihat dalam tokohnya yang berkarakter: (1) kejujuran, (2) disiplin, (3) mandiri, (4) rasa ingin tahu, (5) cinta tanah air, (6) bersahabat, (7) komunikatif, (8) bekerja keras, dan (9) romantis. Kesembilan unsur karakter ini belum pasti bernilai sama dengan unsur karakter bangsa universal. Kesembilan unsur karakter tokoh cerita Si Mardan itulah isi teksnya.

\section{a. Unsur Karakter yang Unggul pada Tokoh Cerita Si Mardan}

Unsur karakter yang unggul pada teks cerita rakyat Si Mardan sesuai dengan filsafat etika penting seseorang untuk berbudi sesuai adab Melayu yang romantis dalam berkomunikasi (Syaifuddin, 2015). Penafsiran peneliti dan pengujian tesis bahwa orang Angkola dan Mandailing pandai berkombur jenaka (Harahap, 2012). Tokoh cerita Si Mardan adalah bersuku Batak Toba yang bervariasi secara genealogis dengan orang Angkola dan Mandailing. Oknum lelaki dewasa sering berkomunkasi dalam kegiatan berkombur atau bercakap-cakap secara lisan yang disertai tindak tutur implikatif yang pragmatis.

Unsur nilai yang universal adalah kemandirian; makanya karakter tokoh cerita Si Mardan boleh diakomodasi sebagai contoh pembinaan moral bangsa Indonesia melalui bidang srudi PPKn di SD hingga Perguruan Tinggi (dengan pengajaran moral Pancasila). Hal ini sesuai dengan Effendi (2009) merupakan tonggak budaya bangsa Indonesia jika ingin berkemajuan (progresif). Dengan mitra bicaranya yang feminim. Hal itu terlihat dalam kalimat dalam kalimat pendukungnya yang tertera dalam tabel dengan kata kunci yang ditunjukkan dalam frase atau klausa dalam deskripsi komunikatifnya. Kejujuran dan disiplin unggul bagi Si Mardan.

Kejujuran adalah unsur nilai yang universal, maka karakter tokoh cerita Si Mardan boleh diakomodasi sebagai contoh pembinaan moral bangsa Indonesia melalui bidang srudi PKn di SD hingga Perguruan Tinggi (Moral Pancasila). Pada masa itu Sang pemuda yang berbisnis dengan juragan atau toke harus mengandalkan sikap kejujuran. Orang Melayu sangat suka kepada sikap jujur. Hal ini termuat dalam peribahasanya: kejujuran bagai cermin apabila retak maka dia takkan kembali sebagai mulanya. Memang Si Mardan terkadang salah dalam bekerja sebagai buruh upahan namun Si Mardan mau mengakui kesalahannya tanpa beralibi atau mengkambinghitamkan orang lain. Dia mau meminta maaf kepada juragannya.

Disiplin, sebagai unsur nilai yang universal dicerminkan melalui karakter tokoh cerita Si Mardan yang boleh diakomodasi sebagai contoh pembinaan moral bangsa Indonesia melalui bidang srudi Pendidikan Kewarganegaraan (PKn) di SD hingga Perguruan Tinggi (Pendidikan Moral Pancasila). Cerita rakyat $S i$ Mardan adalah media pembelajaran yang sesuai Kurikulum Bahasa Indonesia mulai tingkat SD, SMP, 
SMA/SMK/MA. Penyediaan sumbersumber belajar yang terkait dengan upaya pengembangan karakter siswa yang dapat dilakukan melalui cerita rakyat Si Mardan dan Si Malin Kundang (Yunus, 1989).

Cerita ini menarik karena $\mathrm{Si}$ Mardan bersikap romantis kepada gadis. Prasarana sikap lelaki untuk memikat hati orang Melayu. Cerita rakyat Si Mardan dides- kripsikan sesuai rujukan menurut Semi (1984). Konsep Kritik Sastra-nya menunjukkan bahwa tokoh utama dalam cerita $\mathrm{Si}$ Mardan memiliki kompetensi kommunicatif sebagai karakter $\mathrm{Si}$ Mardan (Harahap,2018). "Elements of Character Communicative of Character $\mathrm{Si}$ Mardan. Keunggulannya yaitu pandai memikat hati orang; sikap ini boleh ditiru generasi bangsa Indonesia melalui pengasahan materi peribahasa sebagai sarana kesantunan berbahasa.

\section{b. Unsur Karakter yang Gagal pada Tokoh Cerita Si Mardan}

Nilai-nilai yang nihil yang disikapi Si Mardan terbukti daripada sikap egoistisnya mengabaikan pendapat orang lain untuk memperdulikan Ibunya; namun hal ini terjadi karena Sang pelapor tentang kedatangan Ibunya hendak menemuinya sifatnya berita hoax atau fitnah. Itulah sebabnya Si Mardan bersikap tidak hormat kepada penyambutan orangtuanya yang masih beragama parmalim dan Si Mardan menyangka Ibunya akan marah karena ia telah memeluk agama Islam; Ia termakan berita bohong bahwa Ibunya masih di Kampung.

\section{Pembahasan}

Analisis kegagalan tokoh $\mathrm{Si}$ Mardan berdasarkan nilai karakter ajaran agama Islam. Padahal Si Mardan sudah memeluk agama Islam tetapi masih komprehensip pemahamannya terhadap Al Quran sehingga ada beberapa unsur karakter bangsa yang nihil pada tokoh Si Mardan daripada 18 karakter yang dirujuk. Tokoh $\mathrm{Si}$ Mardan gagal dalam membangun nilai-nilai (1) religius, (2) tanggung jawab kepada Ibunya.

Hal ini terjadi karena pengetahuannya tentang etika menghormati Ibu menurut ajaran Islam belum diketahuinya. Dia belum mempelajari Al Quran yang sesuai dengan surat Lukman. Dengan demikian di dalam suatu kongres perlu diseminarkan topik adab berorangtua versi budaya Melayu.

Deskripsi kisah terfitnah $S i$ Mardan durhaka kepada orang tuanya yaitu Si Mardan masih bersiasat untuk menemui Ibunya yang mungkin $S i$ Mardan masih gengsi kepada istrinya sebagai keturunan orang kaya. Justru Si Mardan karena inginlah ia melihat Ibu kandungnya makanya Si Mardan pulang kampung yaitu pergi berkapal ke Tanjungbalai (Sitorus, 2014). Bacalah buku Kenyataan Asal Usul "Pulau Simardan" Terfitnah Durhaka.

\section{KESIMPULAN}

Tokoh cerita rakyat Si Mardan adalah tokoh cerita yang terfitnah sebagai anak durhaka. Tokoh cerita $\mathrm{Si}$ Mardan adalah tokoh cerita yang memiliki karakter unggul yang memiliki unsur karakter bangsa yaitu jujur dan disiplin.

\section{DAFTAR PUSTAKA}

Alisjahbana, Sutan Takdir. (1989). Budaya dalam Wawasan. Jakarta. Balai Pustaka.

Aminuddin. (1990). Sekitar Masalah Sastra: Beberapa prinsip 
dan metode penerapannya. Malang: Yayasan Asih Asah Asuh. Danandjaja, James. (1994). Folklor Indonesia Ilmu Gosip, Dongeng, dan lain-lain. Jakarta : Grafiti.

Endaswara, Suwardi. Dkk. (Ed,). (2013).

Folkor dan Folklife, Jogyakarta: Penerbit Ombak.

Effendi, R.Ks, dan Shafwan H.Umry. 2017 ,

Si Mardan, Medan: Penerbit Mitra. Harahap, Rosmawati. (2015). "Keliterasian

Karya Sastra Pengarang Sumatera Utara" Jurnal Dialektika. Volume 5. ISSN: 2338-

2635. Jakarta: Fakultas Sastra Univeritas Kristen Indonesia. Harahap, Rosmawati. (2012)." Kombur Jenaka Angkola Mandailing: Analisis Bentuk, Tema, dan Nilai". Tesis. Sintok: COLGIS-Universiti Utara Malaysia.

Harahap, Rosmawati. (2018). "Elements of Character Communicative of Character $\mathrm{Si}$ Mardan". International Symposium Proceeding. Medan: University of Muslim Nusantara Al Wasliyah, February 2018, hlm.301-308.

Jabrohim, (2005), Metodologi Penelitian Sastra, Yogyakarta: Hanindita Graha Widya.

Massardi, Yudhistira Anm. (2016). Bapak, Ibu, Selamatkan Anakanakmu! Bekasi: Media Pustaka Sentra.

Ni Nyoman, dkk.(2013). Mengurai Tradisi Lisan Merajut Pendidikan Karakter. Bali : ATL.

Nurgiyantoro, Burhan, (1995). Teori Pengkajian Fiksi Yogyakarta: Gajah Mada Unversity Press.

Othman Bin Daya, Haji JG. (2006). Tradisi Lisan Bercorak Cerita, Kuala Lumpur: Jabatan Kebudayaan dan Kesenian Negara.
Ratna, Nyoman Kutha. (2010). Sastra dan Cultural Studies Representasi Fiksi dan Fakta. Yogyakarta:Pustaka Pelajar.

Sahril, Ok. (2012). 14 Cerita Rakyat Sumatera Utara, Medan: Penerbit Mitra.

Sitorus, Ayyub Arivin. (2014). Kenyataan Asal Usul "Pulau Simardan" Terfitnah Durhaka.

Sinar, Silvana dan Muhammad Takari. (2015). Teori dan Metode untuk Kajian Tradisi Lisan. Medan: Penerbit Mitra.

Sinaga, Nurti. (2017). "Cerita Rakyat Si Mardan Sebagai Media Pendidikan Karakter: Suatu Pendekatan Didaktis". Tesis. Medan: Pascasarjana UMN Al

Washiyah.

Manasikana. (2007). Teras Sastera Melayu Tradisional.

Syaifuddin, Wan. (2015)." Kebudayaan Melayu: Bergerak dalam Rentak, Rentap yang Tiada Henti”. Jurnal Tifa Volume V. No.1.2015.Medan: Pascasarjana UMN Al Washliyah.

Venus, Antar. (2015). Filsafat Komunikasi Orang Melayu, Bandung: Penerbit Simbiosa Rekatama Media 